\title{
ANÁLISE DE FALHAS EM PEÇA DE ESTRUTURA DE FIXAÇÃO DE AEROGERADOR DE PEQUENO PORTE *
}

\author{
Roberto Abreu Alencar ${ }^{1}$ \\ Renardir Peixoto Maciel Júnior ${ }^{2}$ \\ Enio Pontes de Deus ${ }^{3}$
}

\section{Resumo}

Com o barateamento dos custos de implantação e inovações em estruturas geradoras de energias renováveis, nos dias atuais a demanda de instalação de fontes renováveis de energia tem aumentado exponencialmente. Porém como toda estrutura estas estruturas estão condicionadas a falhas de vários tipos. Neste trabalho apresenta-se uma análise de falha de uma peça, de uma estrutura de sustentação de um aerogerador de pequeno porte voltado a micro geração de energia. Para a condução da análise da falha foram realizados analises microscópicas, fractografias, análises macrograficas e modelagem em elementos finitos. Assim as causas das falhas foram identificadas, como má escolha de materiais e alguns erros no projeto da peça.

Palavras-chave: Análise de Falhas; Aerogeradores; Soldagem.

\section{FAILURE ANALYSIS IN PART OF STRUCTURE OF FIXATION OF SMALL WIND TURBINE}

\section{Abstract}

With the price reduction of deployment costs and innovations in generating renewable energy structures, nowadays the demand for renewable energy installation has increased exponentially. But like all structures these structures are conditioned to failures of various types. This work presents a failure analysis of a part, a support structure of a small wind turbine aimed at micro power generation. In order to conduct the faulure analysis, microscopic analyzes, fractographs, macrographic analyzes and finite element modeling were performed. Thus, the causes of failures were identified, such as poor choice of materials and some errors in the design of the part.

Keywords: Failure Analyze; Wind Turbine; Welding

1 Engenharia Metalúrgica, Graduando, Bolsista, Departamento de Engenharia Metalúrgica e Materiais, Universidade Federal do Ceará, Fortaleza, Ceará e Brasil.

2 Engenharia Metalúrgica, Graduando, Bolsista, Departamento de Engenharia Metalúrgica e Materiais, Universidade Federal do Ceará, Fortaleza, Ceará e Brasil.

3 Engenharia Civil, Professor Doutor, Professor, Departamento de Engenharia Metalúrgica e Materiais, Universidade Federal do Ceará, Fortaleza, Ceará e Brasil. 


\section{INTRODUÇÃo}

Fontes de energias limpas e renováveis estão em alta nos dias atuais, devido às facilidades de financiamento e popularização de instalações domésticas ou de pequeno porte, tendo maiores expoentes as fontes solar e eólica.

Devido a ter uma estrutura mecânica mais complexa, em relação às instalações fotovoltaicas, as torres eólicas estão mais propensas a falhas de ordem estrutural, portanto se deve ter uma maior atenção ao projeto, execução e manutenção de torres eólicas de pequeno porte visto que a instalação destas se dão, normalmente, nas proximidades de residências e locais onde há passagem de pessoas.

Assim existe uma grande preocupação em relação a integridade estrutural destes tipos de estruturas pois, dependendo da gravidade da falha, podem ocorrer graves acidentes.

As falhas em aerogeradores podem ser divididas de duas formas: avarias elétricas, que afetam o sistema eletrônico e de eletrônica de potência do aerogerador, ou defeitos mecânicos que são, defeitos ocasionados por falhas mecânicas das estruturas, normalmente falhas de origem mecânica são consideradas de alta gravidade, pois além do risco de evento catastrófico tem alto custo de reparo.

Segundo [1] as falhas mecânicas mais comuns são relacionadas aos rolamentos do sistema de transmissão de esforços, porém falhas em sistemas de fixação também podem ocorrer, apesar de serem mais incomuns.

Estas falhas têm como razões mais comuns [1]:

- Falta de lubrificação;

- Contaminação da massa de lubrificação;

- Vibrações excessivas;

- Dimensionamento errado das peças;

- Erros de desenho e fabricação;

- Impacto de aves e outros objetos.

\subsection{Análise de Falhas}

Segundo [2] no estudo de análise de falha o analista deve considerar um grande espectro de possibilidades de motivos da ocorrência da falha, pois um grande número de fatores, quase sempre interligados, devem ser entendidos para que se possa determinar a origem primaria da falha. Assim o analista de falhas deve-se encontrar numa posição de um "Sherlock Holmes" quando se está resolvendo um caso de falha de uma estrutura.

Sendo assim a análise de falhas tem como objetivo principal determinar os fatores que influenciaram na falha de uma peça ou mecanismo, sendo esta de suma importância, pois através desta análise se pode corrigir os problemas, de projeto ou de fabricação, assim evitando problemas futuros.

Segundo [3] as causas fundamentais de falhas que podem ocorrer em mecanismos e estruturas são:

- Projeto;

- Seleção de matérias;

- Imperfeições dos materiais;

- Deficiência de fabricação;

- Erros de Montagem/Instalação;

- Condições de operação e manutenção inadequadas. 


\subsection{Princípios de mecânica da fratura}

A mecânica da fratura é a ciência que estuda a forma em que os materiais sofrem falhas e seus mecanismos de falha, assim podendo prever quando uma falha indesejável irá acontecer e também utilizando estes princípios para a realização do que é chamado de "falhas programadas", como no caso da forma de falha de um capô de um carro durante uma colisão frontal, para que exista uma maior absorção de energia por esta peça do carro.

Para materiais de engenharia somente dois tipos de fratura são possíveis, as fraturas frágeis e as fraturas dúcteis, estes tipos de fraturas são divididos pela capacidade de o material sofrer deformação plástica antes da fratura [4].

A cinética usual de uma fratura sempre ocorre em dois passos, a formação de uma trinca e seu posterior crescimento. Assim o tipo e forma da fratura se tornam altamente dependentes do mecanismo de crescimento da trinca, como no exemplo da fratura dúctil onde existe grande estado de deformação plástica na região da ponta da trinca.

\subsubsection{Fratura Frágil}

A fratura frágil é um tipo de fratura em que não ocorre uma deformação apreciável antes que ocorra a fratura, sendo assim o material não consegue entrar em uma região plástica onde ocorre um relaxamento e dissipação de energia de forma de deformação plástica, assim tornando esta fratura repentina e indesejável a qualquer sistema mecânico.

A fratura frágil tem uma morfologia bem definida, e é de fácil distinção, para peças metálicas marcas em forma de Chevron podem aparecer em torno do ponto de iniciação da fratura, também se formam linhas vindas do ponto da iniciação de fratura caracterizando a falha, normalmente estas linhas podem ser vistas a olho nu, porém em metais de com tamanho de grão muito pequeno é necessário o uso de microscópio para identificação destas marcas [4].

\subsubsection{Fratura Dúctil}

A fratura dúctil é um tipo de fratura que ocorre após substancial deformação plástica do material, sendo esta preferível a fratura frágil pois devido a ocorrência de deformação plástica, há tempo para se tomar alguma atitude sobre a integridade estrutural da peça ou mecanismo.

Como mostrado por Callister [4] a fratura dúctil se ocorre em diversos estágios. Após a estricção surgem microcavidades que se formam na secção transversal, com a continuação da deformação estas microcavidades coalescem e formam uma trinca de forma elíptica que continua crescendo na direção perpendicular à aplicação da força até o rompimento total da peça, que normalmente ocorre a um ângulo de $45^{\circ}$, que é o ângulo da deformação cisalhante com o eixo de aplicação da força.

\section{MATERIAIS E MÉTODOS}

Foram analisados 4 (quatro) flanges soldados em eixos que são utilizados na base de fixação do gerador eólico na estrutura de sustentação. Estes componentes falharam em situações de operação e poderiam ter ocasionado acidentes ou incidentes no local instalado e redondezas. Na figura 1 podemos ver as peças analisadas como foram recebidas no Laboratório de Mecânica da Fratura e Fadiga (LAMEFF). 


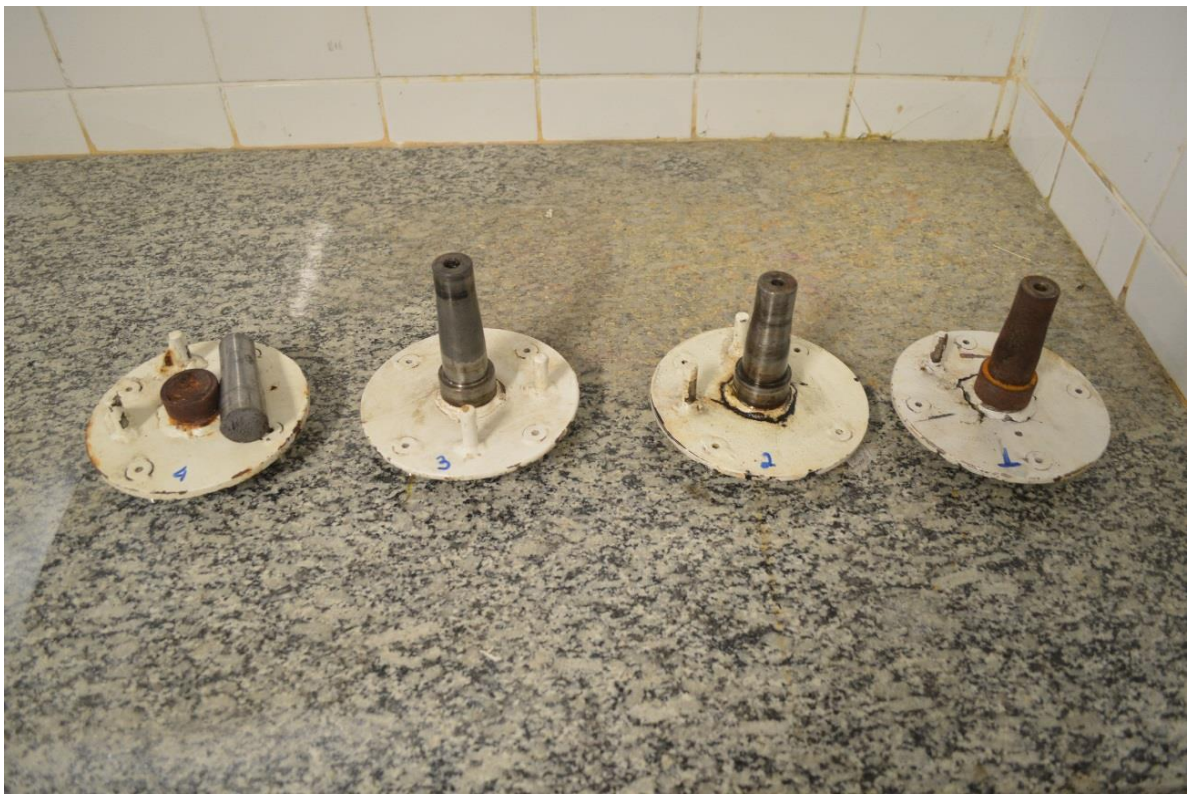

Fonte: Próprio autor.

Figura 1. Eixos soldados aos flanges e numerados, como recebidos.

As peças, após cortes para evidenciar a região de fratura, passaram por analises macrograficas (com o auxílio de câmera digital), analises metalográficas, analise química, por EDS e análise de dureza.

Também foi realizada uma análise de elementos finitos para verificação de dos pontos de maiores tensões do conjunto eixo-flange, quando submetidos a uma carga de torção e a carga de flexão.

\subsection{Preparação da peça}

Inicialmente, foi necessário para se alcançar a região fraturada, as peças foram cortadas com serra manual, o resultado do corte pode ser visto na figura 2.

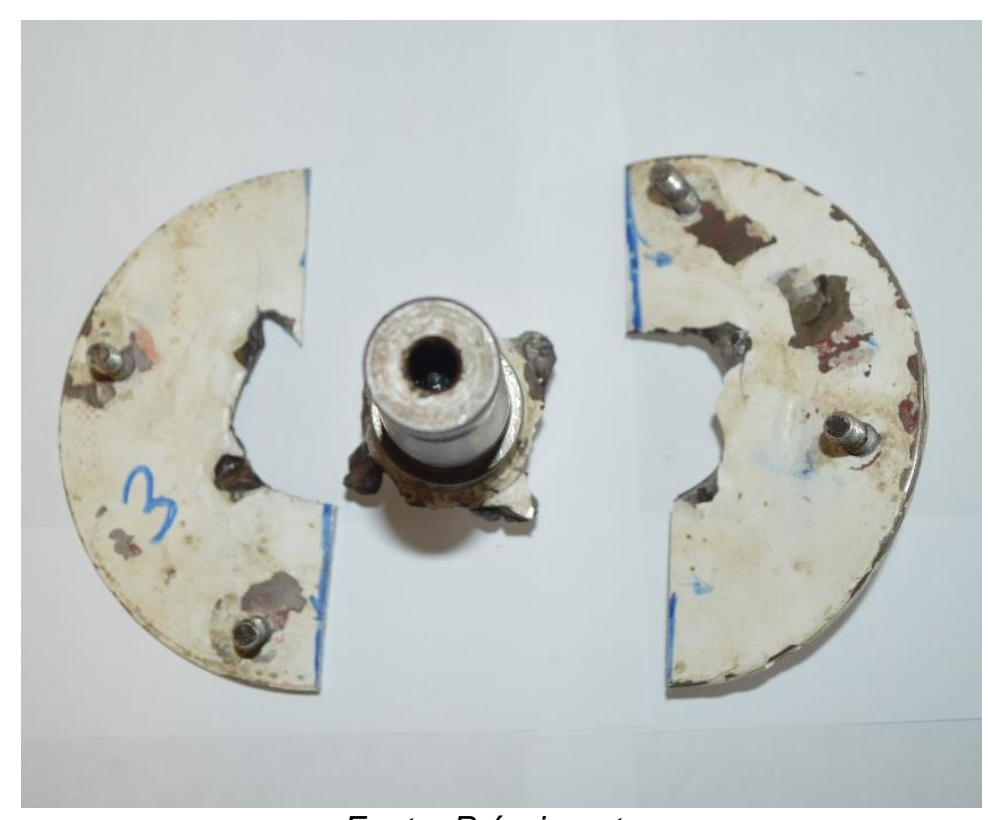

Fonte: Próprio autor.

Figura 2. Eixo cortado para visualização da região fraturada na região de solda 
Após este corte a peça, na região de solda, foi cortada de forma que se tivesse um corte transversal da solda, junto ao material de base, para que fosse feita analise metalográfica da região próxima a solda e análise química da mesma região.

Durante o corte foi percebido em todas as regiões soldadas de todas as peças inclusões e poros que foram analisados por microscopia eletrônica de varredura. Uma peça cortada e lixada para analise microscópica pode ser vista na figura 3.

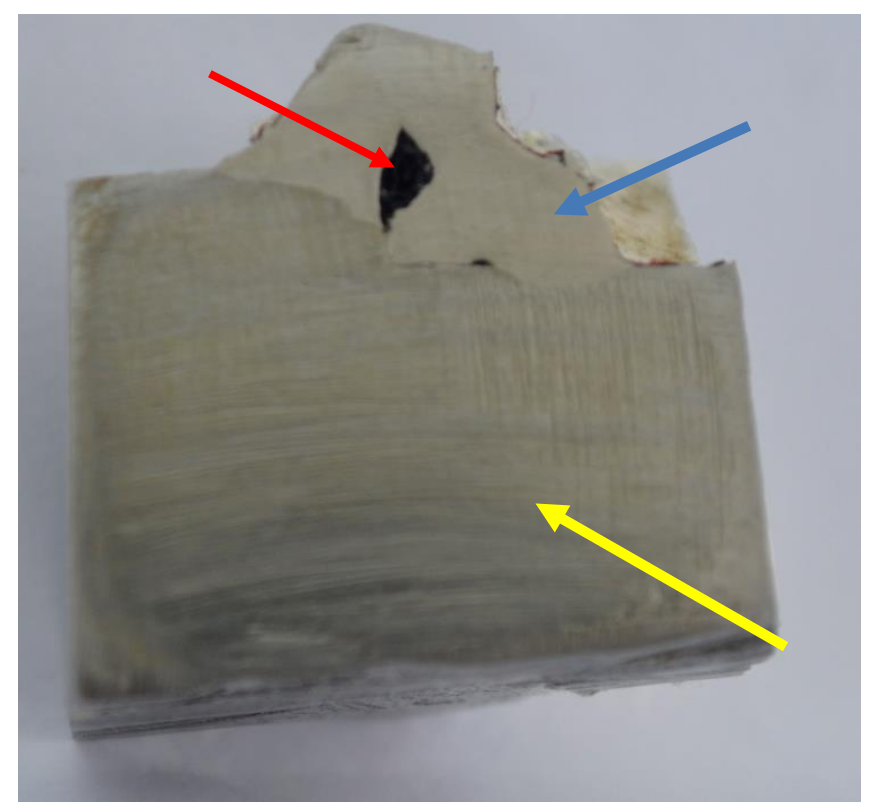

Fonte: Próprio autor.

Figura 3. Peça cortada e lixada, com as setas indicando a inclusão (seta vermelha), solda em inox (seta azul) e região do eixo de aço carbono (seta amarela).

\subsection{Analise em Elementos Finitos}

A análise de elementos finitos foi utilizada para se analisar a resposta a tensão e deformação do material a um determinado carregamento arbitrário, para podermos avaliar os pontos críticos existentes na peça para, podermos comparar com as localizações das peças fraturadas reais, e assim propor modificações nas mesmas para que diminua as regiões de concentração de tensão. Nesta simulação numérica foi utilizado o programa ANSYS 17.0 com uma licença estudantil. Na figura 4 podemos observar a geometria utilizada para a simulação. 


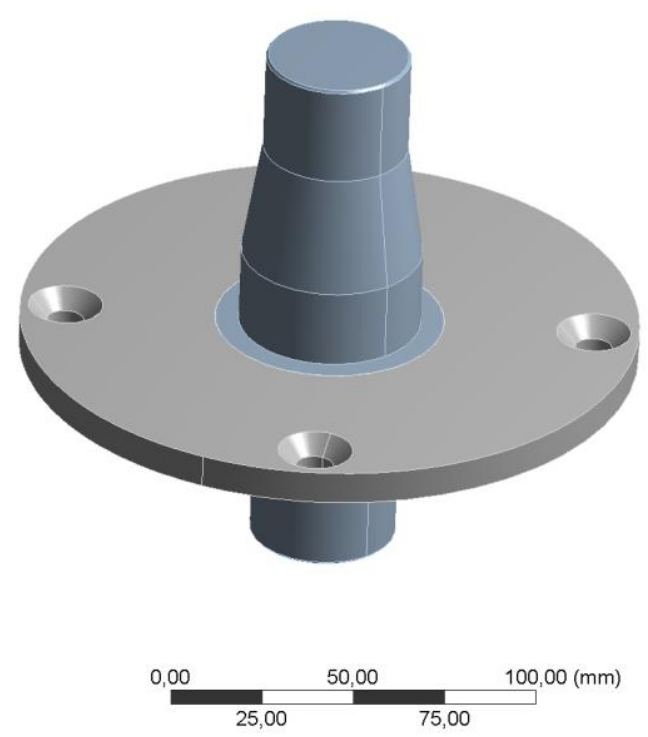

Fonte: Próprio autor.

Figura 4. Imagem da peça que vai ser simulada, com o eixo em azul e o flange em cinza

Para a simulação vamos inicialmente utilizar um modelo estático, para que, analisemos a resposta da estrutura em um caso estático, depois será feita uma análise modal dinâmica para avaliar a resposta dinâmica da peça, para assim ter uma melhor analise sobre a peça, pois a analise dinâmica oferece melhores condições de análise do que uma análise estática.

Para a simulação numérica foi realizada primeiramente a discretização do modelo, nesta discretização foram utilizados 19180 nós e 6188 elementos, sendo a maior parte dos mesmos o elemento solid185, para elementos sólidos e os elementos targe170 e conta174 para a modelagem do contato entre o flange e 0 eixo [5].

Para as restrições aplicadas ao modelo podem ser vistas na figura 5.

\begin{tabular}{l} 
A: Static Structural \\
Static Structural \\
Time: $1, \mathrm{~s}$ \\
$01 / 06 / 201721: 35$ \\
A Fixed Support \\
B Moment: $1000, \mathrm{~N} \cdot \mathrm{mm}$ \\
\hline C Force: $1000, \mathrm{~N}$
\end{tabular}

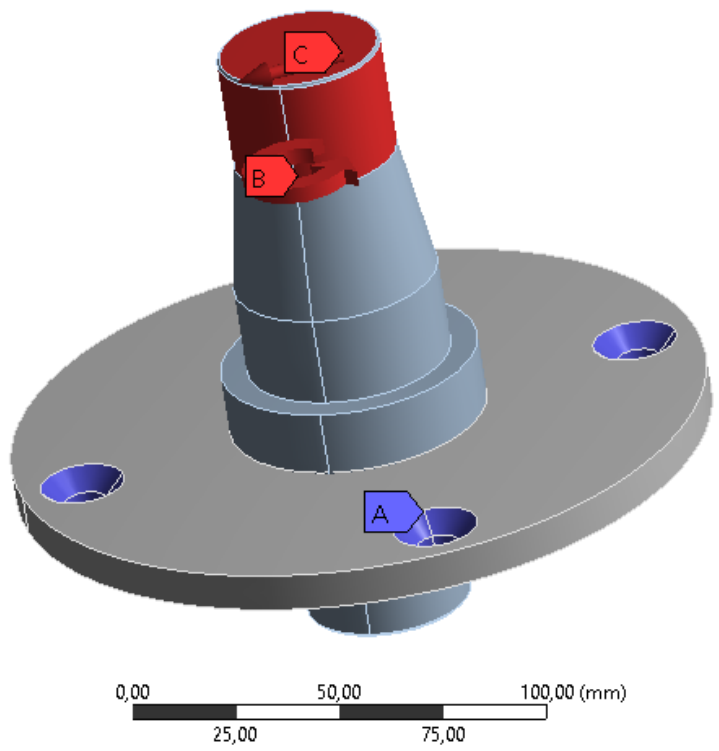

Fonte: Próprio autor.

Figura 5. Restrições aplicadas ao modelo 
As restrições aplicadas não foram obtidas de nenhuma fonte externa ou medição em campo, visto que a simulação numérica foi utilizada neste caso para averiguar as regiões de concentração de tensão no conjunto flange-eixo, porem foram aplicadas restrições que se assemelham às aquelas que existem quando a peça se encontra sob serviço.

\section{RESULTADOS E DISCUSSÃO}

\subsection{Análise visual}

As primeiras análises realizadas nas peças foram as análises visuais, para constatação de tipo de falha onde podemos ver as imagens obtidas nas figuras 6 e 7.

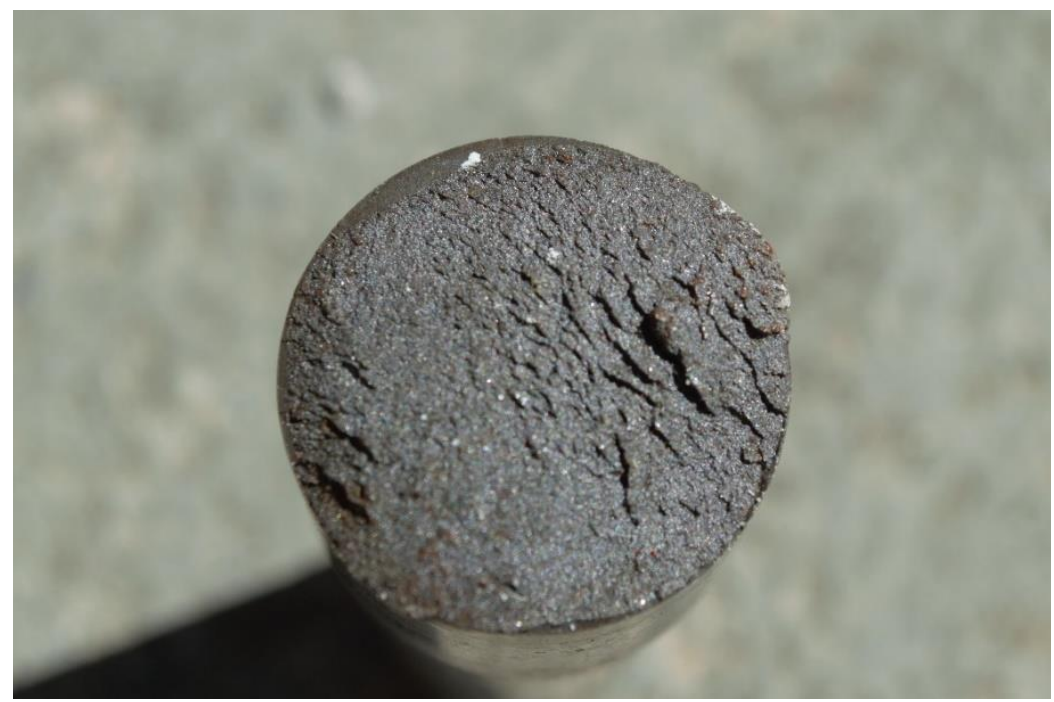

Fonte: Próprio autor.

Figura 6. Figura de eixo fraturado pertencente à peça 4

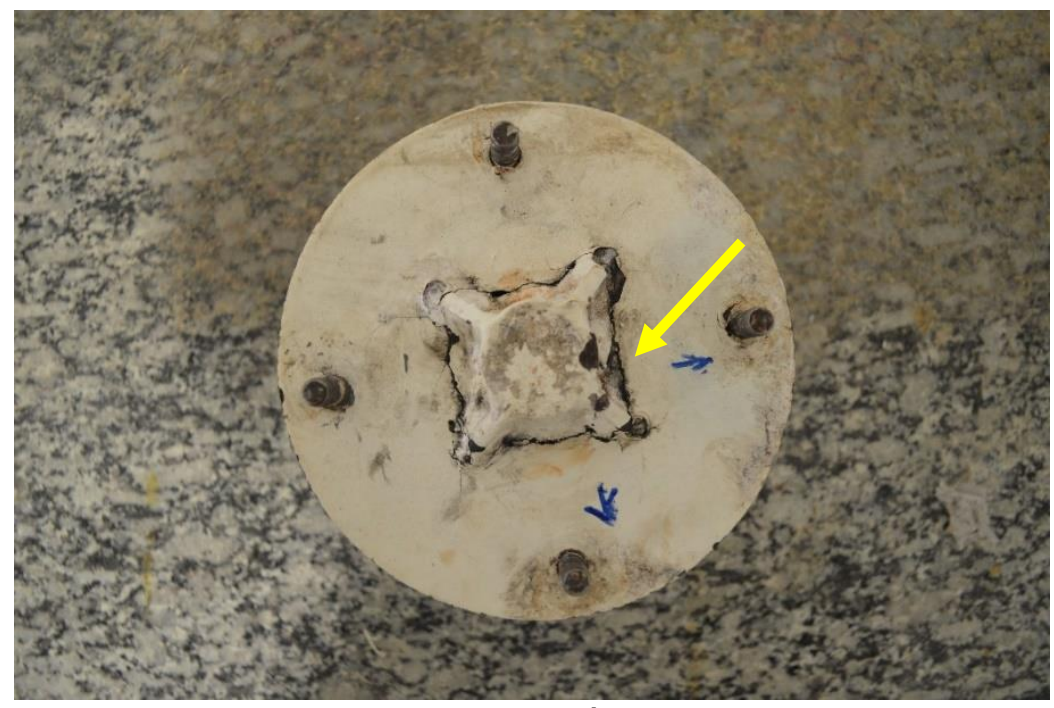

Fonte: Próprio autor.

Figura 7. Peça 1 com região do eixo fraturada indicada pela seta onde a mesma situação ocorre para as peças 2 e 3 .

Podemos observar que tirando na peça 4 todas as fraturas ocorreram na região de solda entre o flange e o eixo assim deixando como opções de defeito, má 
qualidade da solda ou projeto com presença de erros por deixar pontos de concentração de tensão, porem como a peça 4 não apresentou defeito nesta região então foi considerada a primeira opção para as peças 1,2 e 3 e para a peça 4 foi-se considerada a falha devido ao projeto não ter formas de alivio de tensão na região de colapso da peça.

\subsection{Análise Microscópica}

Após realizadas as análises visuais foram retiradas peças da região de solda que foram analisadas em MEV juntamente com a região de fratura do eixo, para realização das imagens e analises de espectrometria de energia dispersiva (EDS) para confirmação da existência de solda dissimilar entre aço carbono e aço inox, fato identificado, não confirmado, na análise visual. A figura 8

As imagens 9, 10 são referentes a analise fractográfica realizada na área fraturada do eixo da peça 4.

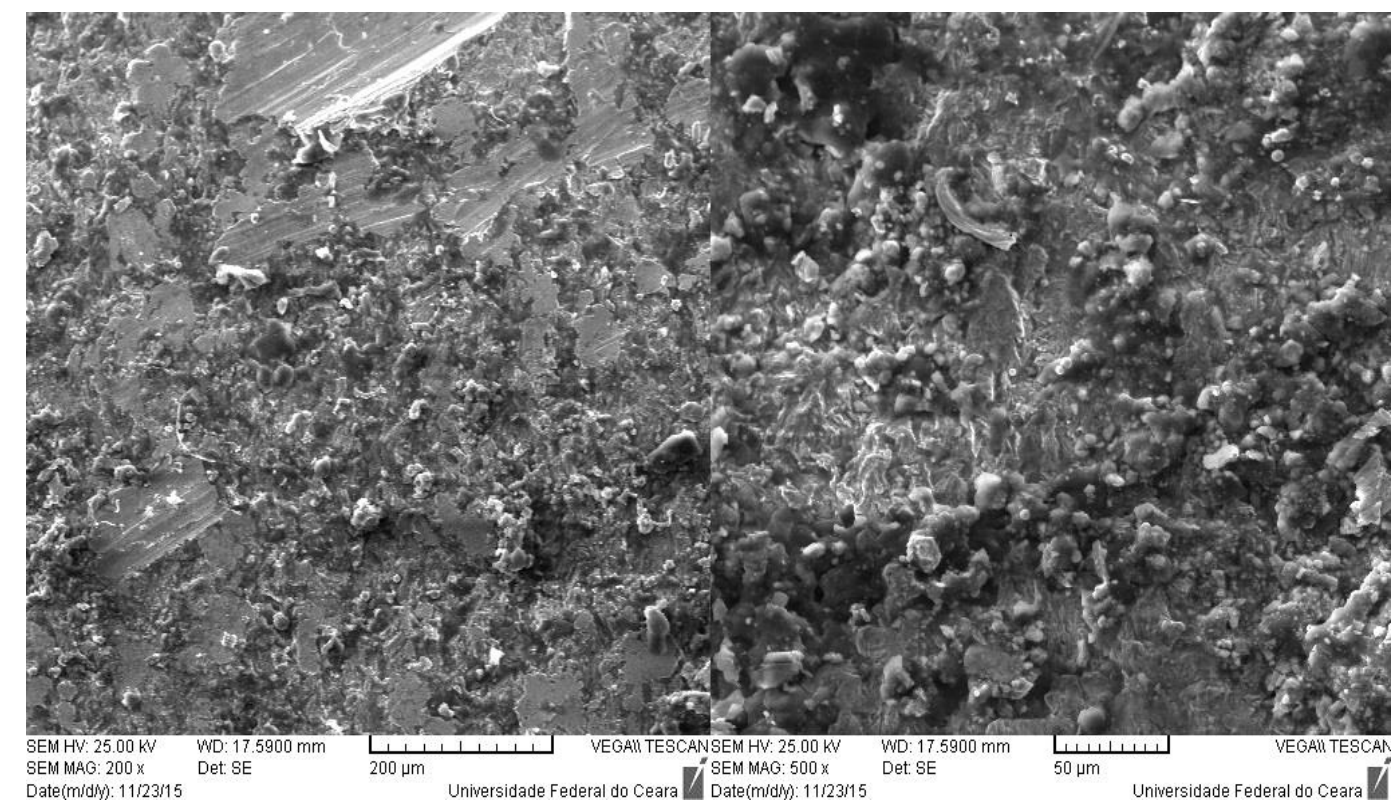

Fonte: Próprio autor.

Figura 8. Imagem referente a região de fratura do eixo da peça 4, próxima a borda com magnificações de 200X (esquerda) e 500X (direita). 

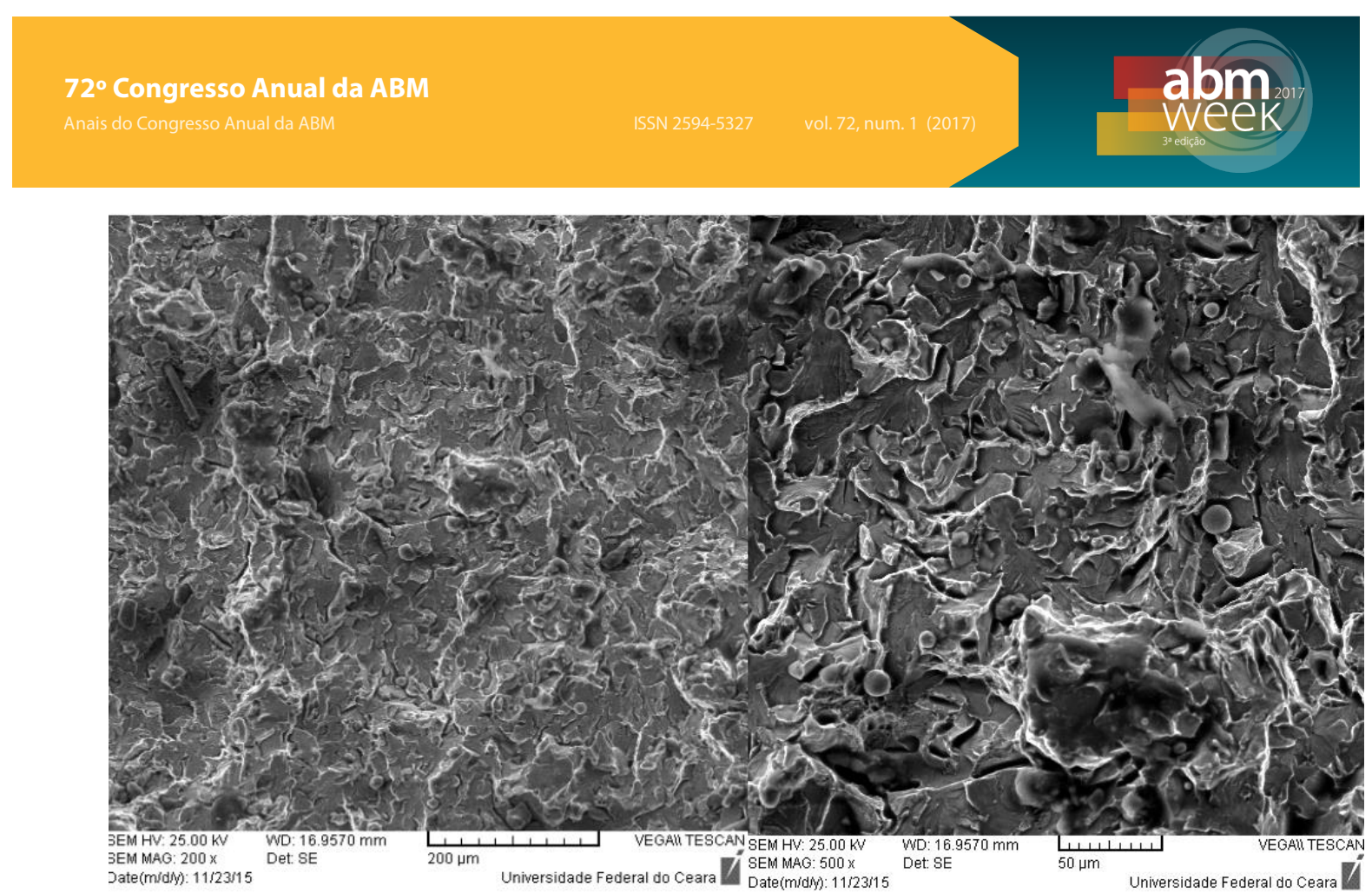

Fonte: Próprio autor.

Figura 9. Imagem referente a região de fratura do eixo da peça 4, no centro da mesma, com magnificações de 200X (esquerda) e 500X (direita).

$\mathrm{Na}$ região interna podemos observar com a magnificação de 500X a existência de microfissuras no material já indicando grade danificação do mesmo durante o serviço. Assim confirmando a teoria em que existe a falha em projeto pois o mesmo deixa perceber pelo nível de danificação que se mostra na superfície de fratura, pois também como se pode observar, a falha praticamente toda tem uma aparência de fratura frágil, assim atentando para a importância da análise mecânica do projeto para que se evitem casos como este.

Já nas peças 1,2 e 3 a falha ocorreu na solda, foi-se constatado a existência de uma solda dissimilar, entre materiais ferrosos, observando a diferença de propriedades magnéticas do material. Para a confirmação desta informação foram feitas analises de EDS que podem ser vistas na figura 10 e 11.

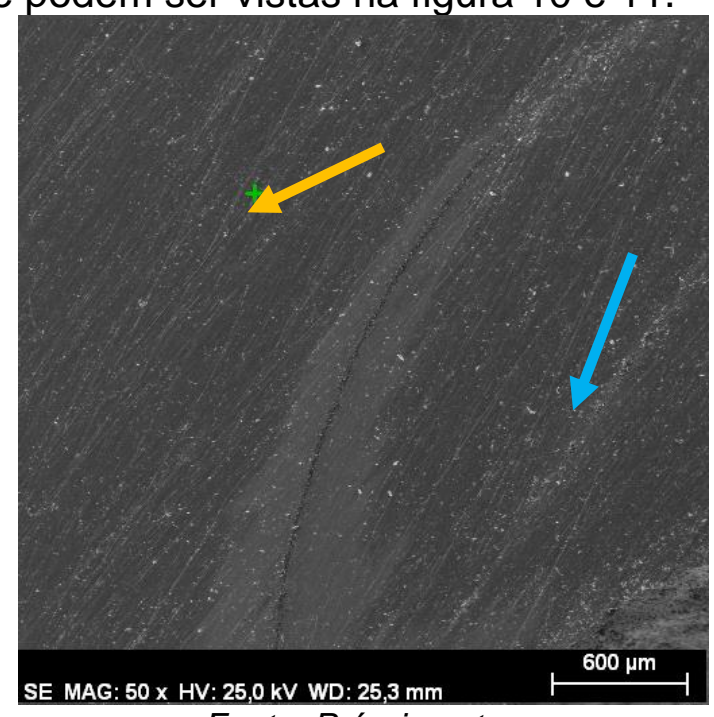

Fonte: Próprio autor.

Figura 10. Imagem referente a uma região de interface entre metal de solda e metal de base pertencente a peça 1 onde indicados pela seta laranja temos uma região de aço carbono e indicado pela seta azul uma região de aço inox, confirmado pelo uso de EDS. 

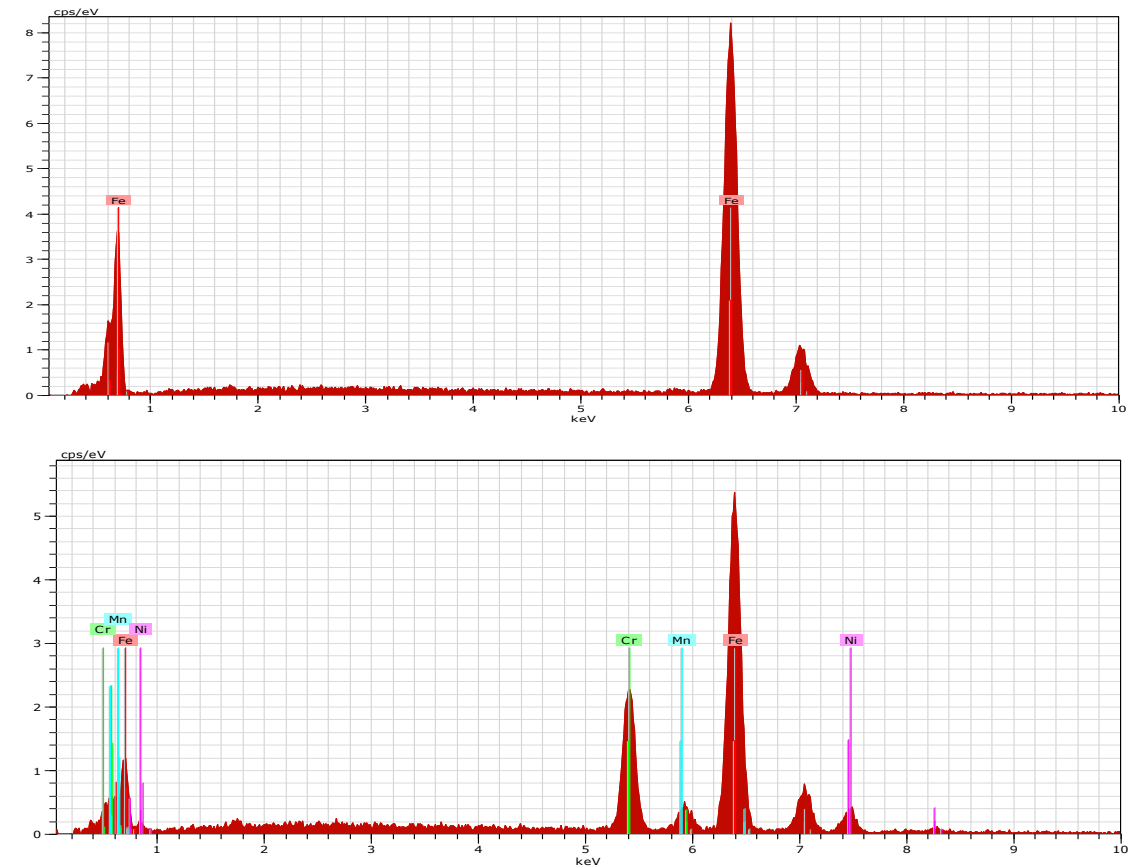

Fonte: Próprio autor.

Figura 12. Resultados de EDS para as análises realizadas na área da peça representada pela figura 11, o espectrograma superior indica a analise realizada no ponto indicado pela seta laranja e o espectrograma inferior indica a analise realizada no ponto indicado pela seta azul.

Podemos observar que no espectrograma superior a ausência de quaisquer outros elementos o que indica que se trata de um aço carbono, porém não temos uma análise quantitativa em relação ao carbono pois o EDS não consegue captar com precisão elementos de baixo peso molecular como o carbono.

Já na análise do espectrograma inferior podemos perceber a presença de cromo, manganês e níquel em quantidades significativas, além do ferro, e devido a presença de cromo e níquel podemos inferir que seja um aço inox, como podemos ver na tabela 1, que é a tabela exportada pelo programa que realizou as análises.

Tabela 1. Resultado da análise de EDS na peça 1.

\begin{tabular}{|c|c|c|c|c|c|c|}
\hline El & AN & Series & unn.[wt.\%] & C norm.[wt.\%] & C Atom.[wt.\%] & C Error[\%] \\
\hline $\mathrm{Cr}$ & 24 & K-series & 18,59 & 18,55 & 19,72 & 0,6 \\
\hline $\mathrm{Mn}$ & 25 & K-series & 1,95 & 1,94 & 1,96 & 0,3 \\
\hline $\mathrm{Fe}$ & 26 & K-series & 72,21 & 72,07 & 71,32 & 2 \\
\hline $\mathrm{Ni}$ & 28 & K-series & 7,45 & 7,44 & 7 & 0,3 \\
\hline
\end{tabular}

Fonte: Próprio autor.

Portanto o fato de se ter uma junta dissimilar na peça indica uma das razoes da falha, que é uma solda de baixa qualidade realizada por operadores, que não tinham o conhecimento para a realização de tal procedimento, um exemplo disso é o fato que em todas as soldas foram observadas a presença de inclusões, que foram analisadas por EDS e se revelaram inclusões de oxido de titânio como podemos observar nos resultados da figura 13. 


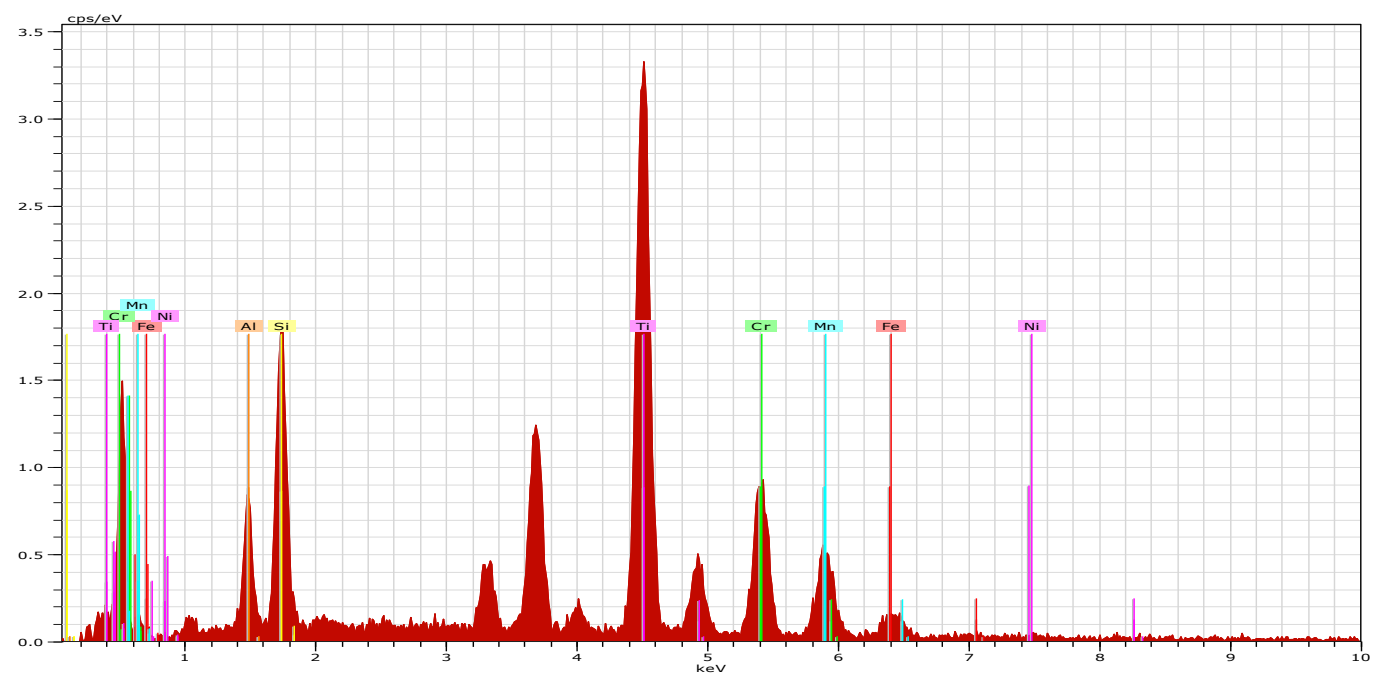

Fonte: Próprio autor.

Figura 13. Espectrograma da inclusão encontrada nos cordões de solda das peças 1 a 4 .

Como podemos observar na figura 13 temos um grande pico de titânio presente no espectrograma assim indicando a presença do elemento na inclusão, o que pode significar que foi utilizado um eletrodo rutílico nesta solda e devido ao acabamento do cordão de solda e a empresa que produziu a peça não ter uma fonte de solda a arame tubular em suas instalações temos que, estas inclusões vêm devido a mal ajuste de solda em um processo de eletrodo revestido utilizando um eletrodo rutílico.

\subsection{Análise de Elementos Finitos}

Para a averiguação dos pontos críticos de tensão existentes na peça foi feito um modelo 3D da mesma e uma simulação numérica utilizando o software ANSYS 17.0 em sua versão estudantil

As imagens 11 e 12 são os resultados da simulação numérica para a tensão de Von Misses, onde se tem um apanhado geral das tensões, visto do estado triaxial de tensões presente no modelo, em um modelo estático e modelo dinâmico considerando somente a vibração natural do modelo.

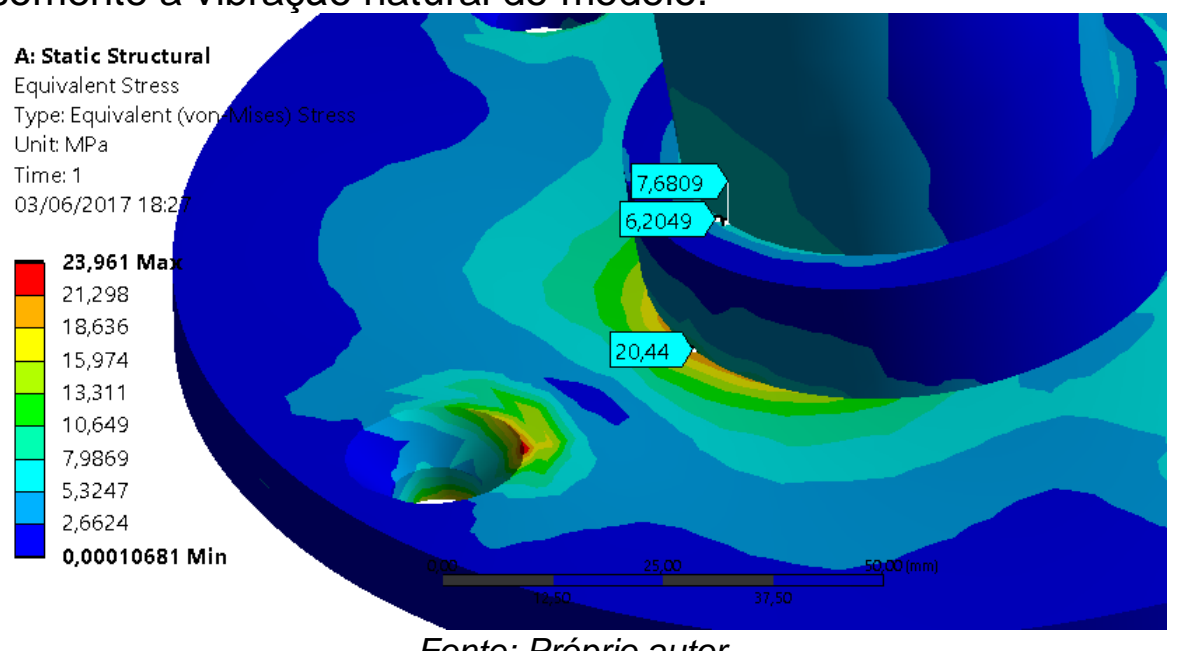

Figura 14. Resultado da simulação estática para a tensão de Von Misses realçando as regiões com concentração de tensão. 


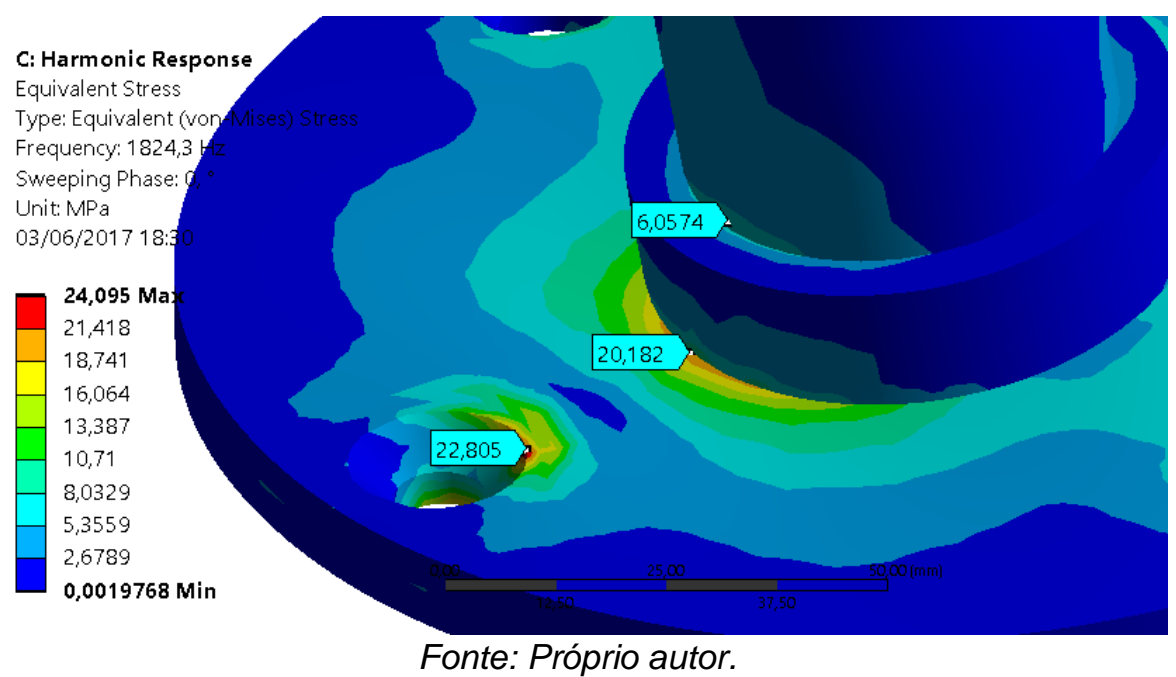

Figura 15. Resultado da simulação numérica dinâmica para a tensão de Von Misses realçando as regiões com concentração de tensão.

Como podemos observar nas figuras 14 e 15 temos um acúmulo de tensão na região de solda assim corrobora com o fato de as falhas acontecerem principalmente neste local, devido da solda de baixa qualidade estar localizada em uma região de concentração de tensão e também corrobora com a falha da peça 4, pois nesta peça tivemos uma solda de melhor qualidade devido a ter materiais mais compatíveis entre si assim, porem temos também uma região de acumulo de tensão na região de falha, e devido a este acumulo de tensão temos uma maior danificação do material nesta região, assim gerando grande quantidade de dano no material que pode ser observada na figura 9.

\section{CONCLUSÃO}

Podemos concluir com estas analises que:

- As peças romperam em regiões com alta concentração de tensão, confirmada por analise numérica.

- A existência de uma junta dissimilar aumentou significativamente a complexidade do processo de soldagem.

- A presença de inclusões de oxido de titânio (rutilo) no cordão de solda diminuiu drasticamente a resistência mecânica da solda.

- A fratura da peça 4 (única que não fraturou no cordão de solda devido a ser a única peça a não ter junta dissimilar) foi frágil devido à grande acumulo de dano na região afetada pela fratura, que foi observado nas fractografias.

Como sugestão de melhoria para esta peça se está o melhor estudo dos esforços presentes na peça para assim poder aplicar uma geometria mais eficiente em termos mecânicos e também uma maior atenção ao processo de soldagem, pois como a região de solda é sempre uma região critica em um projeto, em relação a falhas, se tem de alterar os parâmetros de solda, como aumentar a corrente de soldagem, para evitar a formação de inclusões no cordão de solda. 


\section{Agradecimentos}

A equipe do LAMEFF (Laboratório de Mecânica da Fratura e Fadiga) da Universidade Federal do Ceará por dispor do espaço, conhecimento e infraestrutura para realização do trabalho e ao IPDI pela realização das imagens em microscópio eletrônico de varredura.

\section{REFERÊNCIAS}

[1] Energia, P. Principais avarias eléctricas e mecânicas em Aerogeradores. Portal Energia Energias renováveis. 2011 [acesso em: 03 de junho de 2017]: Disponível em http://www.portal-energia.com/principais-avarias-electricas-e-mecanicas-emaerogeradores-energia-eolica

[2] Wulpi, D. J. Understanding How Components Fail. 2ed. ASM International.1999

[3] Zolim, I. Curso técnico em automação industrial : ensaios mecânicos e análises de falhas. Santa Maria. Colégio Técnico Industrial de Santa Maria . 2011.

[4] Callister, W. D. Materials science and engineering : an introduction. 7ed. Chicago. Jonh Wiley \& Sons. 2007.

[5] ANSYS,Inc. ANSYS Mechanical APDL Structural Analysis Guide. Canonsburg. ANSYS,Inc. 2013. 